\title{
Computer Assisted Endoscopic Transsphenoidal Surgery and Related History
}

\author{
Qinghang Li* \\ Department of Neurological Surgery, Wayne State University, USA
}

*Corresponding author: Qinghang Li, Department of Neurological Surgery, Wayne State University, USA.

Received Date: March 06, 2019

Published Date: March 14, 2019

\section{Mini Review}

One of the classic surgical procedures in the neurosurgery is the transsphenoidal approach to remove lesion of sella turcica area. It can be traced to the early days of neurosurgery appeared in the clinical medicine. Schloffer reported the first successful removal of a pituitary tumor via the transsphenoidal approach in 1906 [1]. It was based on the foundations laid by Hirsch \& Cushing [2-4], continues to be the method of choice for treating most sellar lesions. But at early stage, since the complications such as meningitis, postoperative CSF rhinorrhea, hemorrhage, and postoperative edema, this approach was abandonment for a while. Until One of Cushing's pupils, Norman Dott of Edinburgh, valued the importance of the transsphenoidal operation, and performed it when indicated in related patients. He recognized that the transsphenoidal procedure had fallen into undeserved neglect because of the widespread popularity of transcranial operations [5,6]. According to Horwitz [7], by 1956, Dott had performed 80 consecutive transsphenoidal operations with no deaths and had also developed a lighted speculum retractor that improved illumination of the surgical site. From its inception, one of major issues in transsphenoidal procedure has been focus on the adequate visualization of anatomical structures. As transsphenoidal surgery evolved, technical advancements improved the surgical view of the operative field and orientation. The operating microscope replaced Cushing's headlight and Dott's lighted speculum retractor, and fluoroscopy provided intraoperative imaging. In 1967, Hardy introduced the use of the operating microscope for this procedure [8], and developed and designed his own microsurgical instrumentation, which transformed transsphenoidal surgery. The use of the microscope permitted safer and more effective resections of pituitary tumors and other sellar and parasellar lesions. No deaths or serious morbidities occurred in the first 50 patients who underwent microsurgery. These advances led to the modern concept of microsurgical transsphenoidal procedures in the early 1970s. For the past 40 years, as the development of medical images, computer assisted neuronavigation and endoscope technology, the surgical treatment of pituitary tumor and other sella area lesions have been enter a new stage. In this paper, we will give a review of now clinical used technology related with the transsphenoidal procedures.

Medical images: The most useful medical images for the transsphenoidal procedure in neuronavigation is CT scan. After precisely registration, the anatomical structure of sella areas can be identified during the surgery. According to requests of surgery, other medical images can also be used after co-register. Such as MRI is useful for showing the soft tissue structure such an optic nerve in the surgical field and MRA or CTA is used to show the blood vessel structure such as internal carotid arteries around sella area. Real-time intraoperative magnetic resonance imaging [9] and color Doppler ultrasonography [10] have been applied to the classic transsphenoidal operation in an attempt to decrease morbidity and mortality rates further.

Computer assisted neurosurgery is a relatively new marginal discipline from the mid-1980s that leverages the rapid development and wide applications of computer science and technology in medicine. Computer-guided neuro navigation systems applied to transsphenoidal procedure was started from early 1990s [11]. CAS is an evolving technology after accurate registration that allows nearly real-time anatomic navigation during endoscopic procedure by linking preoperative triplanar CT or MRI images and intraoperative endoscopic views, thus helping the neurosurgeon to identify the vital structures in skull base.

Since the first report of successful endonasal endoscopic resection of pituitary adenomas by Jankowski et al. [11], endoscopic 
transsphenoidal procedure has become the standard procedure for most intrasellar tumors. The transsphenoidal approach provides the least traumatic nasal route to the salla turcica, avoids the need for brain retraction, and offers improved visualization of the surgical field. As a result, the lower morbidity and mortality rates reached when compared with transcranial procedures [12]. The most common complication at the sellar stage is intraoperative CSF leakage with rates ranging from $1.5 \%$ to $6.4 \%$.

Artificial arms and hands applied to the transsphenoidal procedure to help hold the endoscope. It increases the stability of holding endoscope and reduces the errors due to human fatigue during the surgery.

Neuro navigation combined with endoscope provides previse surgical localization and adequate surgical site visualization for the transsphenoidal procedure with minimal invasiveness, reduced incidence of complications, less trauma to important anatomic structures compared with traditional open approaches.

Related complications: according to Chung's report [13] a total of 48848 transsphenoidal pituitary tumor resections were performed in the United States from 2007 to 2011, of which 77.5\% were partial and $22.5 \%$ were complete. CSF leak occurred in $8.8 \%$ of cases. Carotid artery injury and vision loss rates were below $0.1 \%$ in this cohort.

The author presents the evolution of modern transsphenoidal procedure as a dynamic interplay between technology, medical images and computer engineering over the past 100 years [14]. These developments can be attributed to our early stage funding neurosurgeons and related Mastr of Medical images and computer scientists. Today the endoscopic technique brings forth new challenges for this traditional surgery, its development reaffirms the principles laid down by the pioneers of transsphenoidal surgery.

\section{Acknowledgement}

None

\section{Conflict of Interest}

No conflict of interest.

\section{References}

1. Schloffer H (1906) Zur frage der Operationen an der Hypophyse. Beitr Klin Chir 50: 767-817.

2. Cushing H (1909) Partial hypophysectomy for acromegaly. With remarks on the function of the hypophysis. Ann Surg 50(6): 1002-1017.

3. Cushing H (1912) The Pituitary Body and Its Disorders: Clinical States Produced by Disorders of the Hypophysis Cerebri. Philadelphia: JB Lippincott: 296-305

4. Cushing H (1914) The Weir Mitchell Lecture. Surgical experiences with pituitary disorders. JAMA 63: 1515-1525.

5. Dott NM, Bailey P (1925) A consideration of the hypophyseal adenomata. Br J Surg 13: 314-366.

6. Biggart JH, Dott NM (1936) Pituitary tumours. Their classification and treatment. BMJ 2: 1206-1208.

7. Horwitz NH (1999) Library: historical perspective. In: Norman M Dott (1897-1973) (Ed.), Neurosurgery 45: 944-948.

8. Hardy J (1967) Surgery of the pituitary gland, using the trans-sphenoidal approach. Comparative study of 2 technical methods. Union Med Canada 96: 702-712.

9. Steinmeier R, Fahlbusch R, Ganslandt O, Nimsky C, Buchfelder M, et al. (1998) Intraoperative magnetic resonance imaging with the magnetom open scanner: concepts, neurosurgical indications, and procedures: a preliminary report. Neurosurgery 43(4): 739-747.

10. Arita K, Kurisu K, Tominaga A, Kawamoto H, Iida K, et al. (1998) Transsellar color Doppler ultrasonography during transsphenoidal surgery. Neurosurgery 42: 81-86.

11. Jankowski R, Auque J, Simmon C, Marchal JC, Hepner H, et al. (1992) Endoscopic pituitary tumor surgery. Laryngoscope 102(2): 198-202.

12. Cavallo LM, Messina A and Cappabianca P, Esposito F, de Divitiis E, et al. (2005) Endoscopic endonasal surgery of the midline skull base: anatomical study and clinical considerations. Neurosurg Focus 19(1): E2.

13. Chung TK, Riley KO, Woodworth BA (2015) The use of image-guidance during transsphenoidal pituitary surgery in the United States. Am J of Rhinology \& Allergy29 (3): 215-220.

14. Liu JK, Das K, Weiss MH, Laws ER, Couldwell WT (2001) The history and evolution of transsphenoidal surgery. J Neurosurg 95(6): 1083-1096, 